\title{
Road Traffic Accidents (RTAs) Trends on Kathmandu-Bhaktapur Road after Addition of Lanes
}

\author{
Guru Prasad Adhikari \\ Department of Roads, Kathmandu, Nepal \\ Email: salyaniguru@gmail.com
}

Received 26 March 2016; accepted 29 May 2016; published 1 June 2016

Copyright (C) 2016 by author and Scientific Research Publishing Inc.

This work is licensed under the Creative Commons Attribution International License (CC BY). http://creativecommons.org/licenses/by/4.0/

(c) (i) Open Access

\begin{abstract}
Road traffic accidents are the outcome of the factors associated with the traffic system namely road users, road environment and vehicles. Despite good road surface, the Kathmandu-Bhaktapur road has high accident records. The traffic police record shows that 1530 accidents have occurred from July 2009 to June 2012. The area of study of this research is the Kathmandu-Bhaktapur road which starts at Tinkune Kathmandu and ends at Suryabinayak with a length of 9.1 kilometer, a section of Araniko highway heading towards China. The road is the first ever six lane road constructed in Nepal. The objectives of this research work are to identify locations with high accident numbers, to investigate possible causes of accidents, and to propose countermeasures for traffic safety along the Kathmandu-Bhaktapur road.
\end{abstract}

\section{Keywords}

Traffic Safety, Driver's Age, Driver's Gender, Vehicle Lane, Accident Characteristics

\section{Introduction}

Nepalese roads are one of the most dangerous in the world and chances of vehicle crashes are more than 100 times higher than in Japan and 10 times higher than in India. One person died in every accident in Nepal in the last year. According to Traffic Police data, more than 10,000 people have died because of road accident since 2006. This figure was more than people killed during peoples' war from 1996 to 2006 in Nepal. The loss of lives and property due to road accident is enormous. Estimated mortality rate per 100 thousand populations in Bhutan is 14.4, in Thailand 25.4 and in India 16.8 where the figure in Nepal is 15.1 [1].

The Kathmandu-Bhaktapur road, $9.1 \mathrm{~km}$ in length, is a part of Araniko Highway that extends from Tinkune, 
Kathmandu to Suryabinayak, Bhaktapur. The road traverses through city areas of two districts and gateway to China. The road was built in 1972 and remained two lanes until 2011.This road has been widened and upgraded under the grant of the Government of Japan in 2011. The road is Nepal's first ever six lane highway. Although the road is upgraded, road traffic accidents are increasing day by day. Before 2011, Kathmandu-Bhaktapur road was a two lane road. There were no provisions of road furniture such as medians, sidewalks and sufficient lights throughout the roads. Bridges at Jadibuti and Hanumante were two lanes which were narrow with respect to the traffic. Road improvement work was started in 2008 with an objective to improve the traffic condition of the Kathmandu-Bhaktapur road and utilizing the old bridges at Manohara and Hanumante. The road has been upgraded and widened into six lanes, medians have been constructed throughout road length, bridges have been extended and lights are provided at each junction. Compared to other roads of the Kathmandu valley; the geometry, road surface, and road furniture in this road is better. However, the safety situation is not as expected. The GIS Map of Kathmandu Bhaktapur Six lane road is shown in Figure 1.

\section{Traffic Growth along the Road}

There was a significant growth of traffic observed after the opening of the six lane road. The increasing trend of Annual Average Daily Traffic (AADT) in the Kathmandu-Bhaktapur road from 2007 to 2012 is shown in the Figure 2. The traffic has been increased significantly to 49,192 AADT in 2012 compared to 21590 AADT in 2007 [2].

\section{Speed Analysis}

A spot speed study was carried out by recording the speeds of sample vehicles in Jadibuti area. Speed characteristics identified by such a study are valid only for the traffic and environmental conditions that exist at the time of the study [3]. Figure 3 shows the average spot spread of bikes, cars, buses and trucks plying in the Kath mandu-Bhaktapur road in different hours of a day. The design speed of this road is $80 \mathrm{kmph}$ which determines

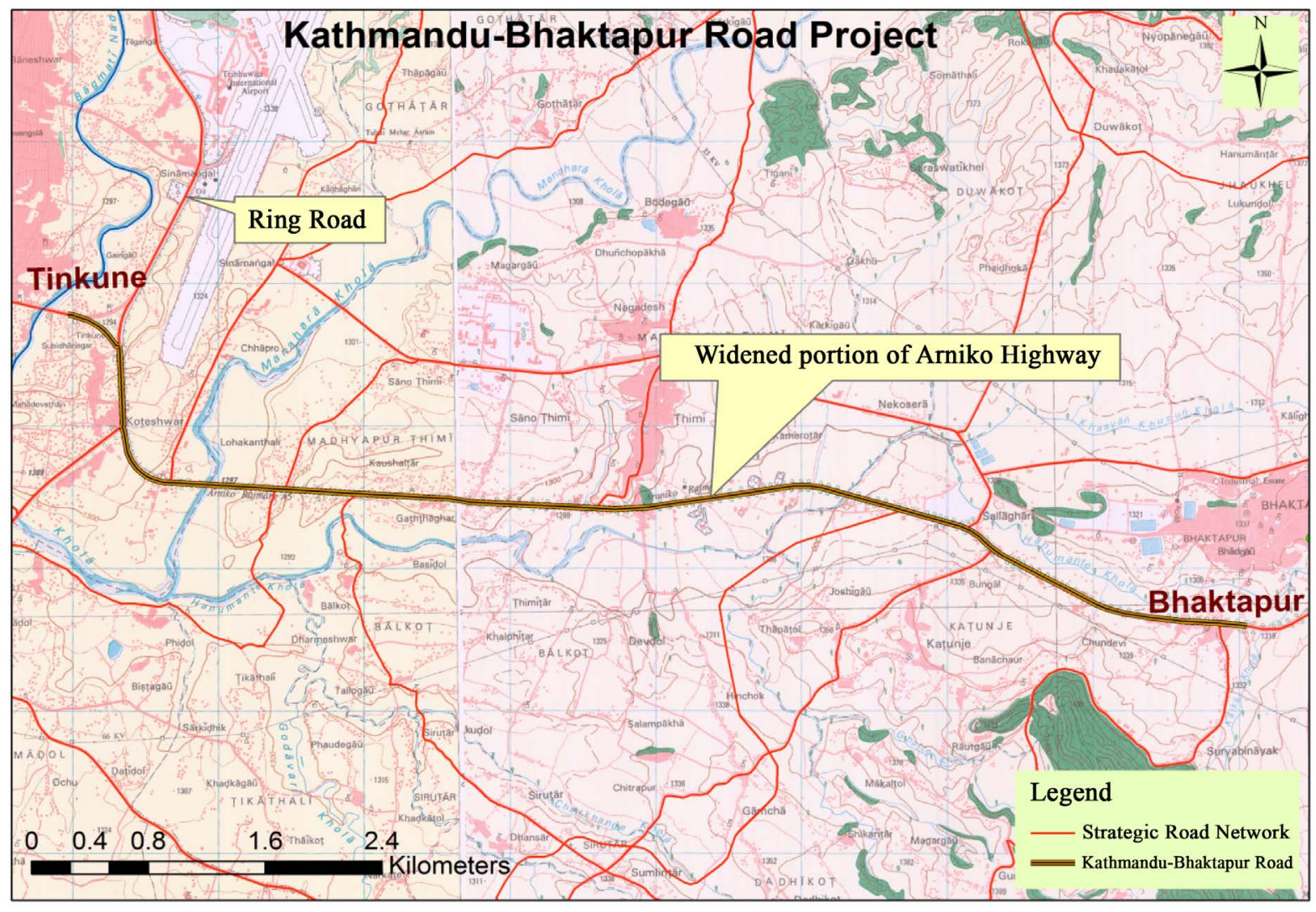

Figure 1. GIS MAP of Kathmandu-Bhaktapur Six lane road (DoR, 2012). 


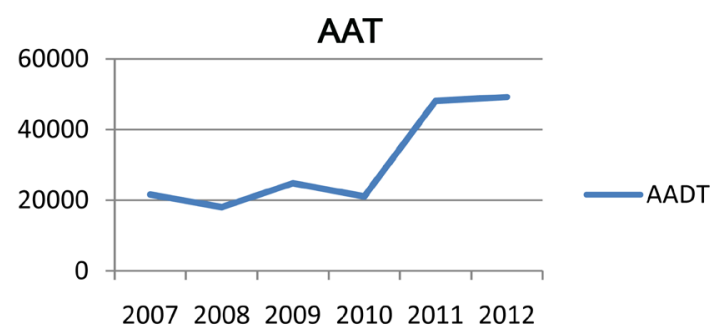

Figure 2. Traffic growth along Kathmandu-Bhaktapur road.

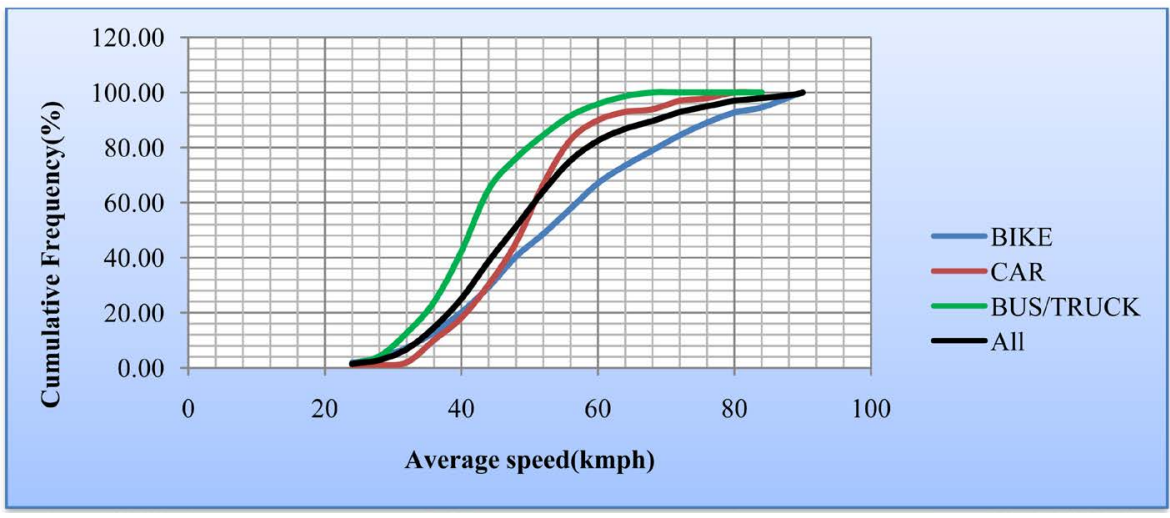

Figure 3. Spot speed of vehicles.

the design parameters and the safe speed limit set for vehicle operation is $60 \mathrm{kmph}$ as the road passes through urban area. Speeds were measured from 9:30 AM to 10:30 AM, 12:30 PM to 1:30 PM and 6:30 PM to 7:30 PM in three different hours of the $2^{\text {nd }}$ of June 2013. Speed during 12:30-1:30 was higher in comparison to other two hours.

The 85 percentile speed of the bus and trucks is $53 \mathrm{kmph}$, that of car is $55 \mathrm{kmph}$, and it is $76 \mathrm{kmph}$ for bikes. This shows that majority of bikes are travelling with higher speed. Trucks and buses were found to be travelling within the speed limit. To regulate and control speeding towards reducing accidents in this road, newly brought radar speed meter for speed checking should effectively be in operation to inhibit speeding.

\section{Accident Characteristics}

As per accident data of traffic police along Kathmandu-Bhaktapur Road, from June 2009 to July 2012 total of 1530 accidents were reported in which 1219 were minor injured, 243 were major injuries, and 68 were fatal respectively as shown in Figure 4. Accidents reported in the years of construction were 462 and 554 and after construction the data reported was 514 .

There is an increase in accidents immediately after completion of the road. This is due to two reasons: the first one is the speed of vehicles got limited because of the obstructions and construction safety measures installed in the road during construction and the frequencies of accidents were less, and most of the accidents during that period were minor. The second reason is road users were unfamiliar to the changed behavior and features of road. On the other hand, when the road was in full operation in the next year vehicle travelled with higher speed and accidents were higher. Accidents are decreased in the year 2011/012. This is due to the result of awareness programs conducted by Kathmandu-Bhaktapur road project office, various institutions and media partners focusing safety to road users. Another reason behind this is that people slowly got familiar with the changed features of the road.

\section{Analysis of Accident by Time}

\subsection{Analysis of Accident by Months}

Figure 5 shows the distribution of accidents in relation to months of the year 2010/11. There is downward pat- 


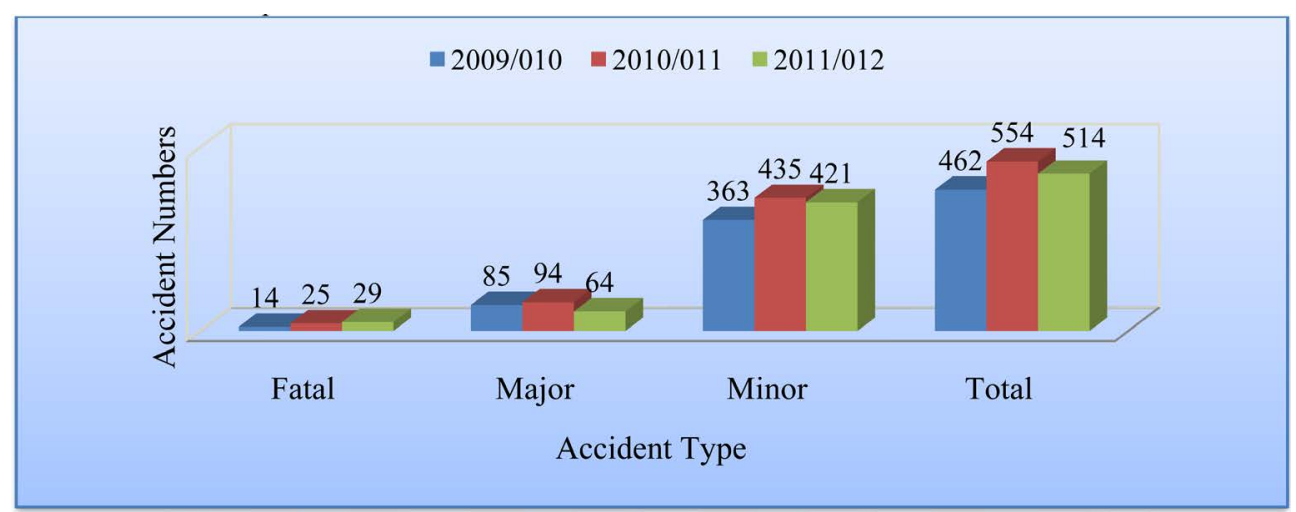

Figure 4. Accident type.

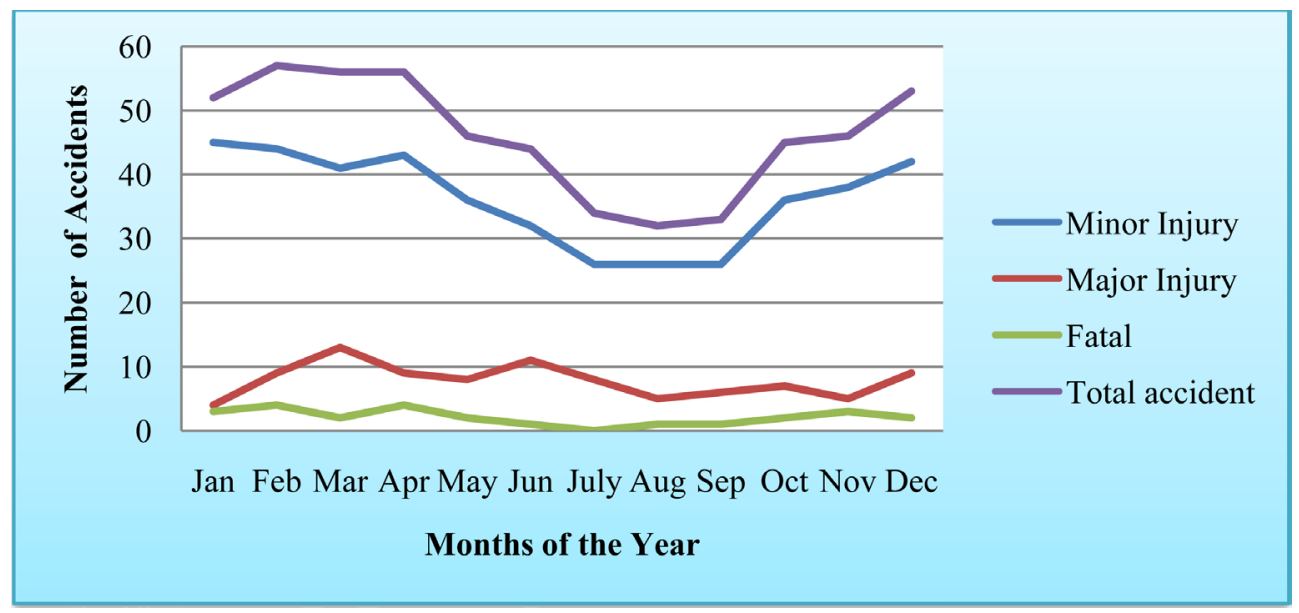

Figure 5. Monthly accident variations.

tern from April to July and upward from September to February and like a plateau from February to April. Accident in August is the lowest and in February it is highest in number.

Almost equal numbers of road users are using the road every month i.e. there is not seasonal variations in the flow of people in particular months of the year. The reason for higher accidents during the months of September and October is due to the pedestrians flow in selling and buying of goods because of the festivals like Dashain and Tihar. Drivers also consume alcohol during these festivals. There are fewer movements of vehicles transporting construction materials during the months of June, July and August because of less construction activities. Also during interviewing with bike riders, some of them said that they don't ride bikes in extreme cold days during winter due to poor visibility and the low temperature. As a result of these two reasons the accidents may be lowered in the months of June, July, August, November and December.

\subsection{Analysis of Accident by Days of Week}

Figure 6 shows the distribution of accident with respect to days of week. Tuesday has the lowest accident rate amounts to be $10 \%$. There is increasing trend from Tuesday till Thursday. Wednesday and Thursday have the highest accident percentage. Monday has the second highest value. There is no significant variation in accidents among the days of week. The Kathmandu valley is the place of God and Goddess and people go to temples in Monday and Thursday for religious belief and as a result accident might have been peaked up.

\subsection{Analysis of Accident by Hours of a Day}

The distribution of accident with respect to different hours of day is as shown in Figure 7.

The graphical presentation shows that accident corresponding afternoon hours (12:00 - 15:59) are the 


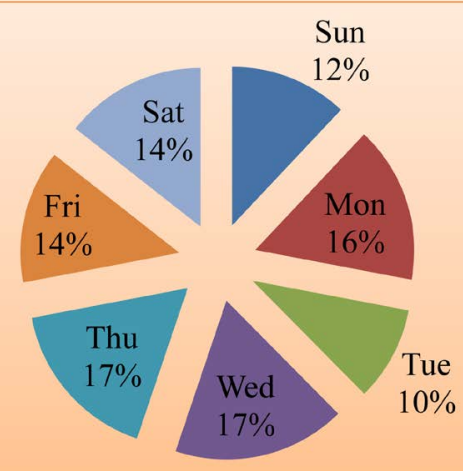

Figure 6. Daily accident distributions.

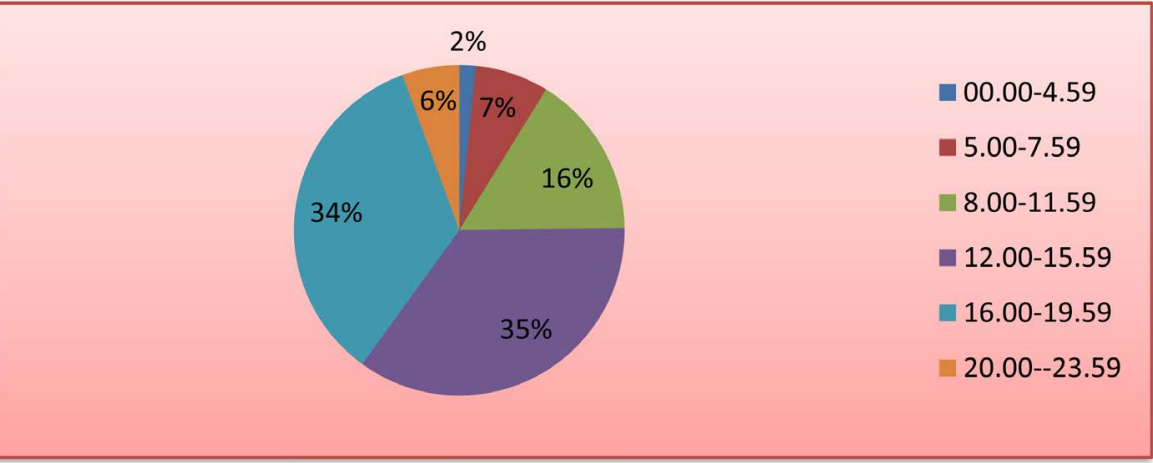

Figure 7. Hourly accident distributions.

highest and the lowest during mid night to early morning (00:00 - 4:59). Accidents during the hours from 00:00 to 8:00 hours are lower and are increasing from 8:00 am to $8 \mathrm{pm}$. Accidents are highly concentrated in afternoon hours (12:00 - 15:59). Next to this is evening hours (16:00 - 17:59). There is almost no flow of pedestrians from $8 \mathrm{pm}$ to $4 \mathrm{am}$. So, there is less chance of accidents during this period. From 8 am to 12 it is office hours and mostly careful driving is prevailed in the road. So accidents are less in numbers during this period. Afternoon is the non-office hour, vehicle density being lower and drivers driving with higher speed might be the reasons of higher accident. Also, evening hour is the next period where accidents are in the second rank. This is due to stressed and fatigued drivers because of continuous work and visibility.

\section{Accident by Age Group of Drivers}

As per Figure 8, over 66\% of drivers of the age group from 15 to 34 years are involved in accidents. Age group of drivers between 25 and 34 is most active in the economy; they are the one who often use roads. They constitute $41 \%$ of total accidents. Age group of 35 to 44 years involve in an accident by 20 percent. Drivers aged between 15 and 24 occupy 25 percent of total accidents. Similarly, drivers more than 45 year's age occupy 14 percent. The more involvement in accident by the age group of drivers is immaturity due to age and inexperience in driving skill.

\section{Accidents by Vehicle Types}

Accident data on this road indicated that motorbikes were frequently involved in accidents (45.5\%). Figure 9 shows that the second and the third types of vehicles involved in the accidents were micro bus car van and jeep (23\%) and buses (16.5\%) respectively.

Figure 10 shows the types and numbers of vehicles involved in road accidents during the study period. The pedestrian collision with vehicles was significantly higher than other types. Jay walking by pedestrians, driver fatigue with the speed and impatience of motorbikes is the cause of accidents. 


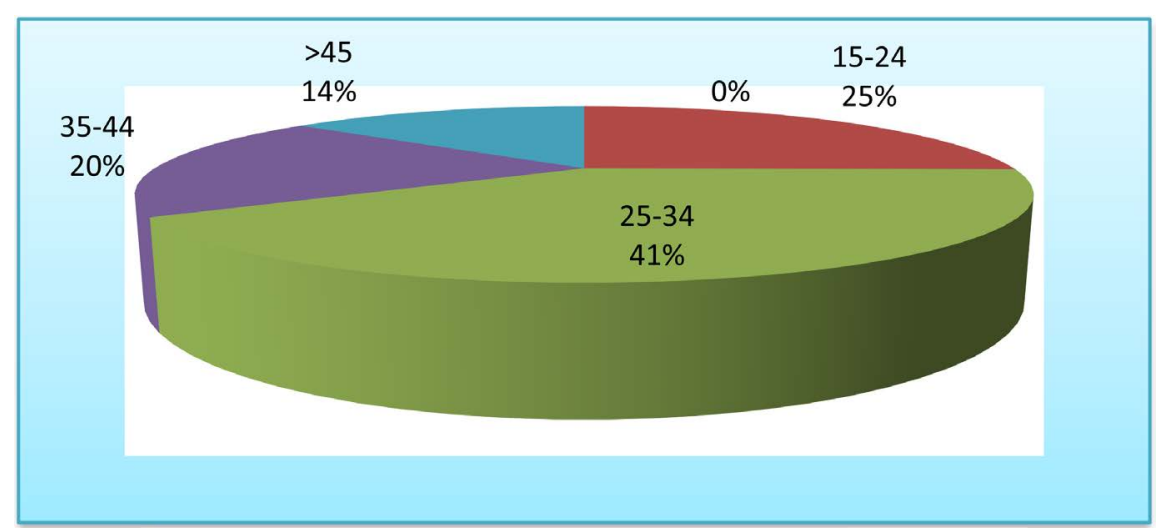

Figure 8. Age group of drivers involved in accident.



Figure 9. Vehicle involvement.

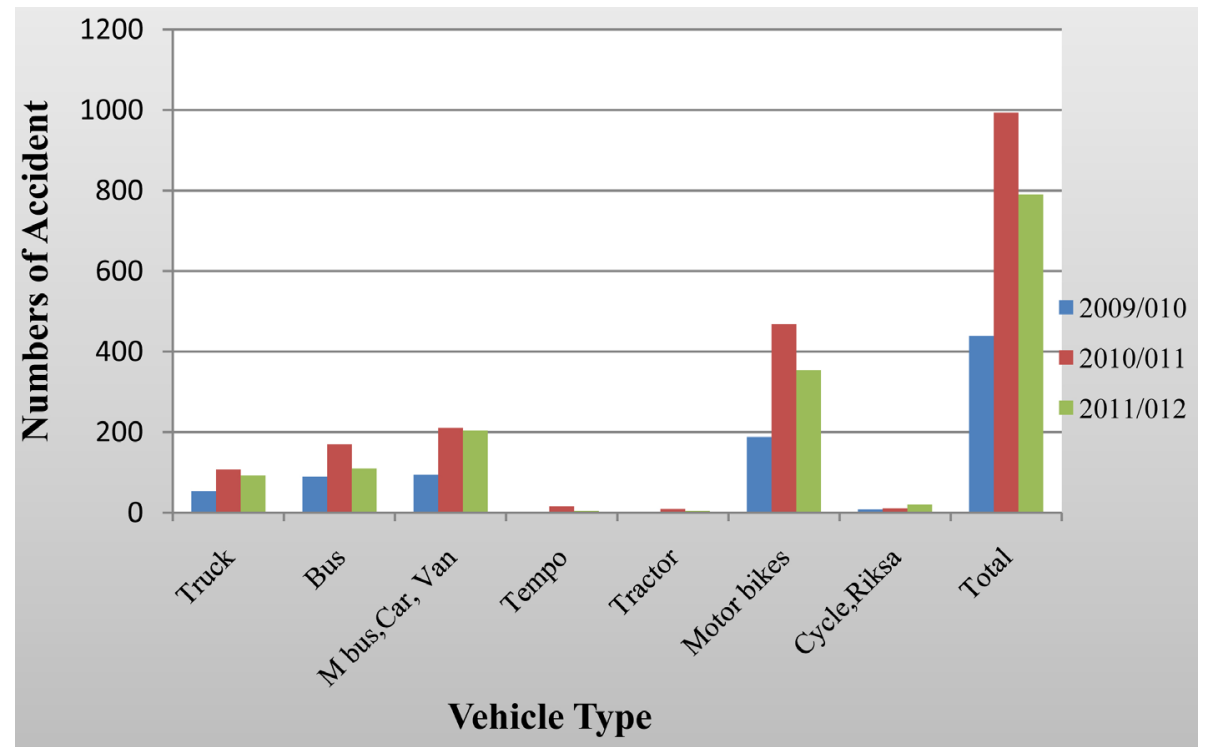

Figure 10. Vehicle involvement.

Figure 11 shows the section wise distribution of accidents in the Kathmandu-Bhaktapur road. Accident prone sections of the road are Thimi-Sallaghari and Tinkune-Jadibuti section.

Thimi-Sallaghari and Tinkune-Jadibuti sections are the most accident prone areas. About 33\% and 29\% accident are happening in these two sections. The first reason being the drivers' psychology while entering into wider roads and the second being higher traffic flow from access roads. Road safety measures have been 


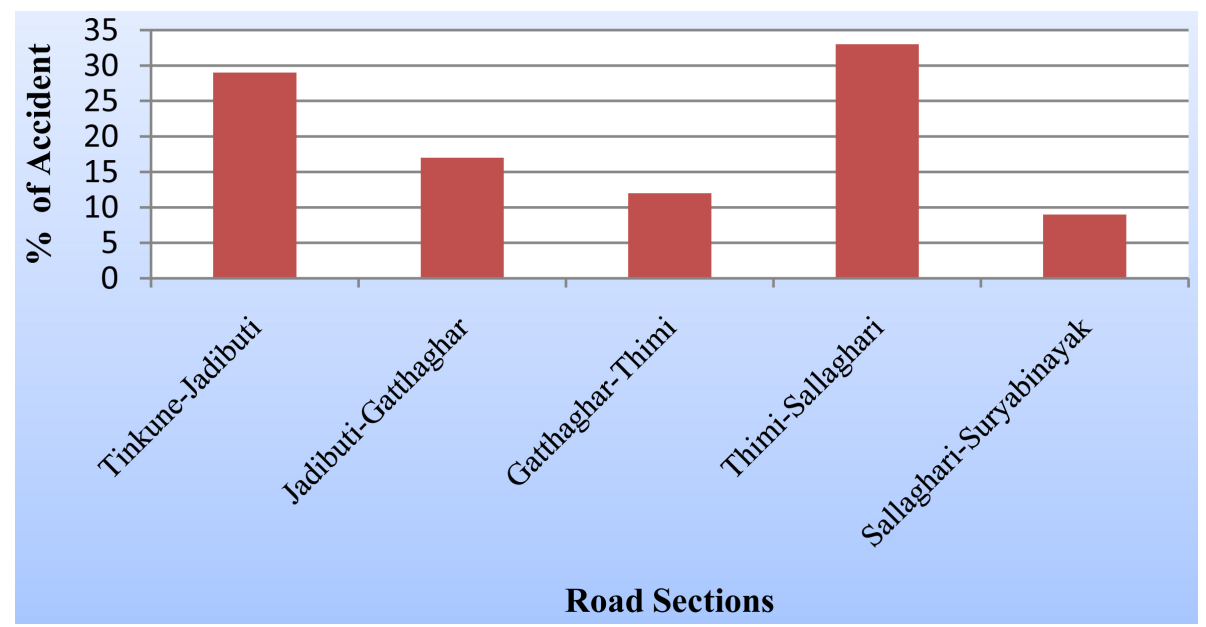

Figure 11. Section wise distribution of accident.

along the road corridors by using Regulatory, Warning and Informatory signs by the Department of Roads and Metropolitan Traffic Police. According to the speed measurement data, vehicles close to a number 2841 plying in six lane road namely tippers, trucks and motorbikes are violating speed limits during the radar gun checking from Kartik 2069 to Jestha 2070 BS (Metro Politian Traffic Office Sallaghari). Traffic Police has experience that drivers of trucks and tippers, and bike riders respect rules only in the presence of them otherwise they violate it. So, for short term result, awareness and strict enforcement both are needed to speed limit violation.

\section{Causes of Accident}

The important factors to road accident are human, vehicle and environment. Among them human is the most significant one. Treat (1980) reports that human factor contributes to road accident by 95\%. Figure 12 shows the causes of accidents on the road. Causes of accidents remain careless, over speeding, vehicular defect, overtaking and drink driving.

Careless behavior of road users is the main cause of the accident observed from the data analysis. $83 \%$ of the accident happened due to carelessness. Next to this over speed is another cause of accident occurrence (10\%) followed by the vehicle defect (3\%) and drink driving and overtaking each (2\%). Data analysis from secondary source (Metropolitan Traffic Police, Singh Durbar) shows that careless driving and walking behaviors of road users is the main causes of accident in this road. These behaviors should be changed to reduce accidents and save lives of people from accidents. The careless behaviors can be changed by taking extra care outside schools, near buses and ice cream vans where children might be around.

\section{Gender Involvement in Accident}

Figure 13 shows the fatal accidents in the Kathmandu-Bhaktapur road during the three year study period. 68 persons including male, female and children have lost their lives during the period. Majority of fatal accidents are males, then female and finally children are victimised.

Trend of fatal accident in case of males shows that it has increased in the year 2010/011 with respect to 2009/010 and decreased in the year 2011/12 with respect to 2010/011. But in the case of female and children fatal accident it is in increasing trend. Accident data show that males' involvement in a road accident is higher than that of females'. This is due to the psychological violent nature of male than female and male ratio involving in outdoor works is higher than females. Also most of the bike riders younger and they drive with higher speed.

Figure 14 shows that major accident involvement of all genders during the three year period. A total of 243 persons are involved in major accident.

Figure 15 shows minor accident involvement during the study period. The numbers of person involved in accidents is 1219. Male involvement in the accidents is increasing every year where as involvement of female and 


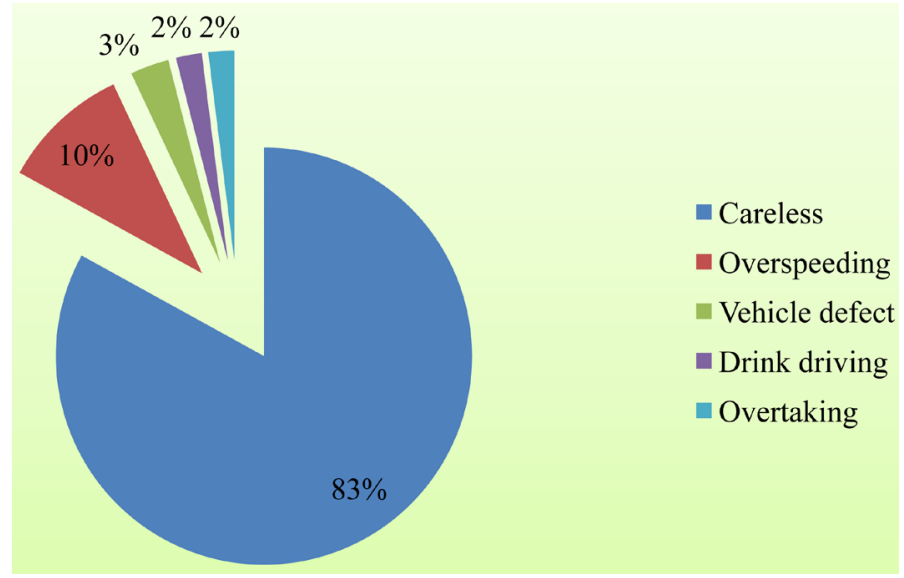

Figure 12. Causes of accident.

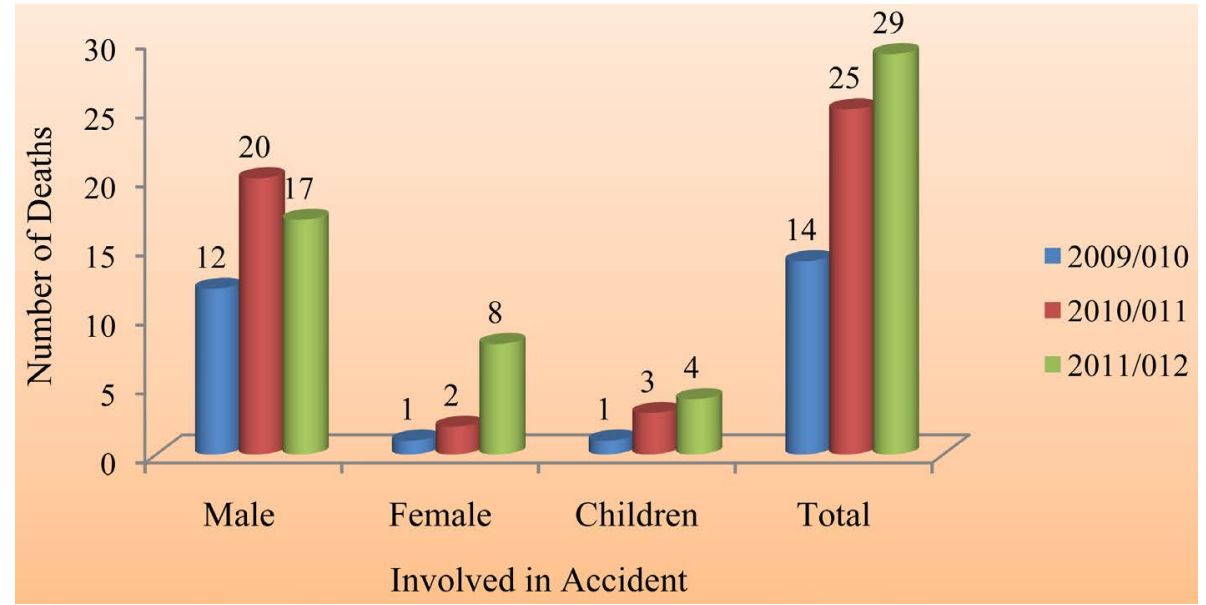

Figure 13. Fatal accident.

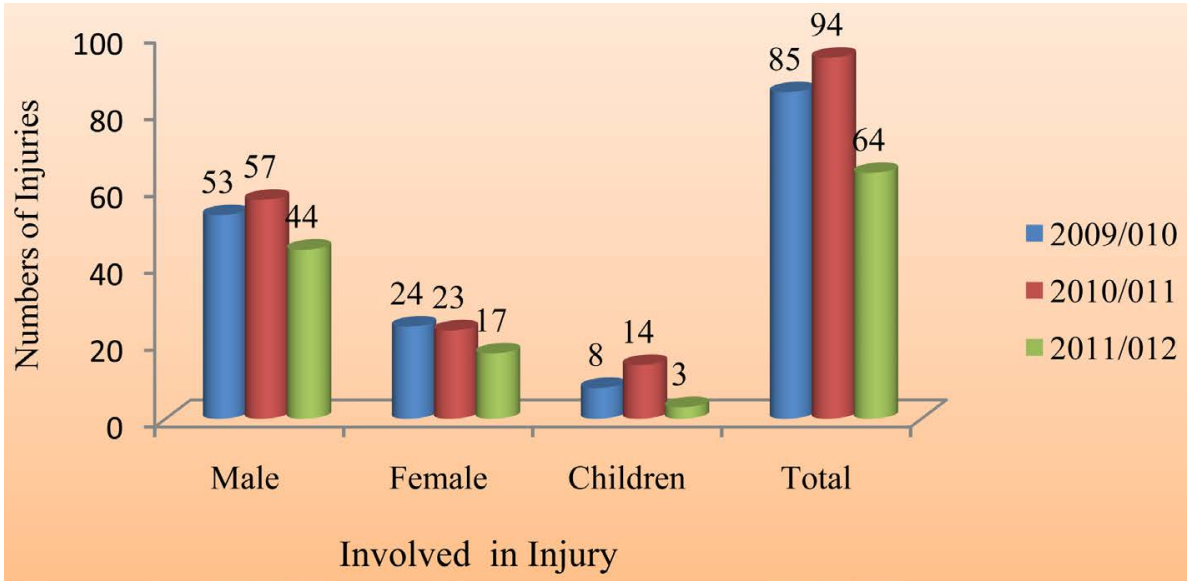

Figure 14. Major injury.

children has increased just after opening of road and decreased in the next year. Both major and minor accidents are following the same pattern i.e. cases increased just after opening of road and the decreased in next year. Major and minor accidents were recorded even when vehicles were travelling with lower speed. Speed enforcement and Awareness programs have helped to reduce accidents in the road. 


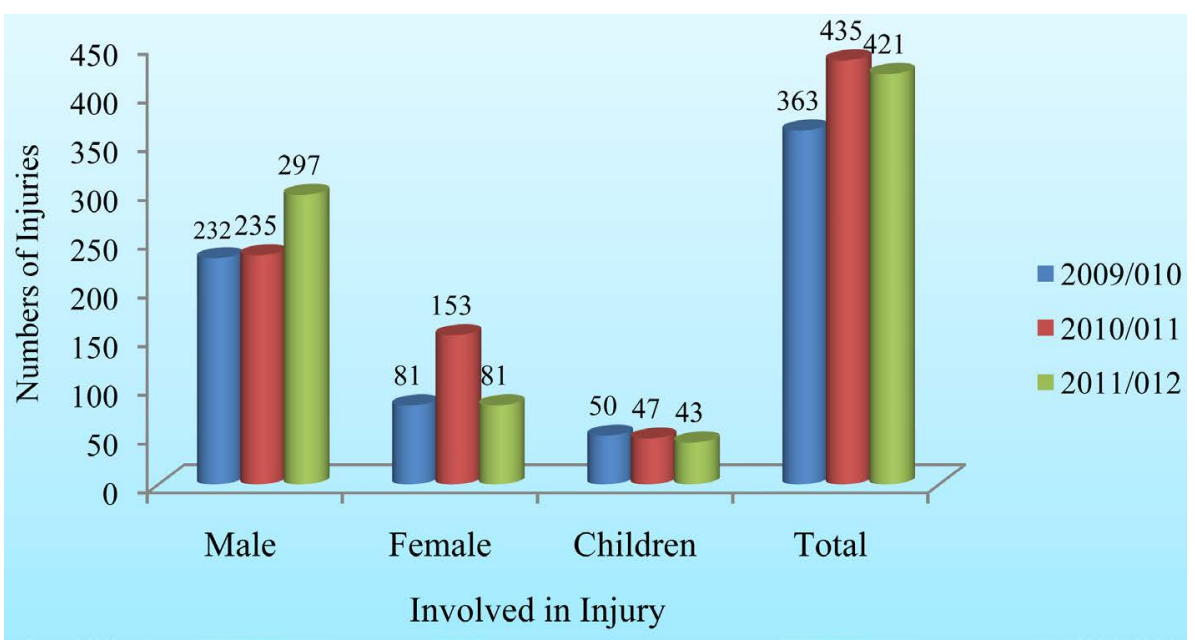

Figure 15. Minor injury.

\section{Conclusion and Recommendations}

There is an increase in accident immediately after completion of the widening of road and decrease in the successive years. This is because of unfamiliarity among drivers with the increased design speed and unchanged behavior of pedestrians. The rate of accident is decreasing after passage of some time as a result of awareness program conducted by the project office and media partners focusing safety of school children, bike riders, drivers and pedestrians. Sallaghari-Thimi and Tinkune-Jadibuti are the sections with higher number of accidents. Main contributing factors of road accidents in this road are: carelessness, over speeding, defective vehicle, drink driving and overtaking. Age is another major cause of accidents; 25 - 34 years age group is found to be the vulnerable group (41\%). Accidents corresponding afternoon hours (12:00-15:59) are the highest (35\%). Motorbikes major mode of transportation is involved in accidents (45.5\%). The reason being motorcycles consists of more than half number of total vehicle plying in this section and major violation of traffic rule being made by them. Males' involvement in road accidents is higher than females' corresponds to the higher males who are involvement in outdoor works along with their more aggressive nature. Following recommendations are made to ensure the traffic safety along the Kathmandu-Bhaktapur road.

1. Stringent enforcement of the provisions of the VTMA for traffic rule violators. Continue and promote drunken driving testing drive.

2. Priorities for behavioral changes by immediate actions such as road campaigns and visual demonstrations. Conduct awareness and training program for drivers to raise the level of understanding and skills.

3. Installation of traffic signs in each section and grade separated intersections at Jadibuti and Sallaghari intersection.

\section{References}

[1] WHO (2009) Status of Road Safety 2009. World Health Organization, Regional Office for South East Asia, India.

[2] DoR (2012) Traffic Data. Department of Roads (DoR), Kathmandu.

[3] Garber, J., Hoel, A. and Sarkar, R. (2010) Principle of Traffic and Highway Engineering. CENAGE Learning. New Delhi 